\title{
Quantitative measurement of the PCCC area in the postoperative period
}

\author{
Y Van Tenten, V De Groot, F L Wuyts, M J Tassignon
}

\begin{abstract}
Backgroundlaims-The major complication of extracapsular cataract extraction (ECCE) is posterior capsule opacification (PCO). Posterior continuous circular capsulorhexis (PCCC) seems to be very promising in preventing PCO. This study was aimed at determining if the PCCC area changes as a function of time and if pearl formation could influence it.

Methods-24 eyes of 23 patients underwent ECCE with PCCC. Retroillumination photographs were taken at 6 months and then yearly. To measure the PCCC area, the computerised program EPCO (evaluation of posterior capsule opacification) was used. The ratio of the PCCC area in relation to the IOL surface was calculated for the different time stages and the presence of pearl formation was noted. Firstly, proportional changes in diameter were compared in PCCC areas measured after 6 months and after 1 year (group $I, n=13$ ) and after 1 year and 2 years (group II, $n=14$ ). Secondly, PCCC areas were compared between two time stages in patients with (group III, $n=19$ ) and without pearl formation (group IV, $\mathrm{n}=8$ ).
\end{abstract}

Results-No statistically significant difference was found in diameter change in either group. The PCCC area remains stabile between 6 months to 1 year and 1 year to 2 years. No differences are found between eyes with or without pearl formation.

Conclusions-The PCCC area remains stable as a function of time and is not influenced by pearl formation. (Br f Ophthalmol 2000;84:1117-1120)

Posterior capsule opacification (PCO) or aftercataract is a major complication of cataract surgery, caused by the proliferation and migration of lens epithelial cells (LECs) left in the capsular bag after extracapsular cataract extraction (ECCE).$^{1-3}$ As soon as cell migration occurs in the visual axis, patients will experience a decrease in visual acuity. The incidence of PCO is estimated to be $20-50 \%$ within 5 years after surgery. ${ }^{1}$ Two major forms are clinically distinguished-pearl formation and fibrosis. The standard treatment for PCO is neodymium:YAG (Nd:YAG) laser capsulotomy. ${ }^{1}$ However, apart from being very expensive, it has been associated with retinal detachment, increase of intraocular pressure, cystoid macular oedema and damage to the intraocular lens (IOL). Several techniques have been advocated to reduce the incidence of PCO, including extensive intraoperative polishing of the anterior and posterior capsules, ${ }^{4}$ the use of lenses with posterior convexity to ensure closer IOL-capsule contact, ${ }^{5-7}$ and application of several antimitotic drugs or antiLEC immunological agents. ${ }^{8}{ }^{9}$ More recently, the intraoperative removal of the central part of the posterior capsule by creating a posterior continuous circular capsulorhexis (PCCC) was proposed. ${ }^{10-13}$ The rationale for this technique was that in the absence of support for the LECs to migrate, no proliferation in the visual axis would occur. However, this statement could not be confirmed by clinical or experimental studies. ${ }^{11}{ }^{12}{ }^{14} \mathrm{Up}$ to now, it is not known whether the PCCC area undergoes changes as a function of time as a result of cell proliferation, fibrosis, or contraction. The purpose of this clinical study was to measure the PCCC area as a function of time using a commercial available computerised program developed for the evaluation of posterior capsule opacification (EPCO). ${ }^{15}$

\section{Materials and methods}

Between 1993 and 1997 PCCC was performed in uncomplicated cataract extraction of 24 eyes of 23 adult patients without any medical or ocular history. Patient ages ranged from 39 to 90 years (mean 65). All patients were operated for cataract by one surgeon and the same surgical technique was used to remove the crystalline lens. Phacoemulsification was performed through a $4.5-5.0 \mathrm{~mm}$ anterior capsulorhexis using a standard two handed divide and conquer technique. The epithelial cells lining the internal surface of the anterior capsule were aspirated and the capsular bag was partially filled with sodium hyaluronate (Healon). The posterior capsule was punctured at the centre with a 19 gauge needle. Healon was injected through the hole to fill Berger's space until the central $4.0 \mathrm{~mm}$ of the anterior hyaloid was separated from the posterior capsule. A $3.0-4.0 \mathrm{~mm}$ PCCC was performed using a capsular forceps. All patients had a one piece poly(methyl methacrylate) (PMMA) IOL implanted in the capsular bag after it was refilled with Healon. Healon was aspirated from the capsular bag and the anterior chamber. The cornea was closed with one 10-0 nylon suture. A subconjunctival injection of methylprednisolone was administered at the 12 o'clock position. The postoperative treatment consisted of the instillation of two different eyedrops, indomethacin and a combination of neomycin and prednisolone, four times daily lasting for 1 month. 

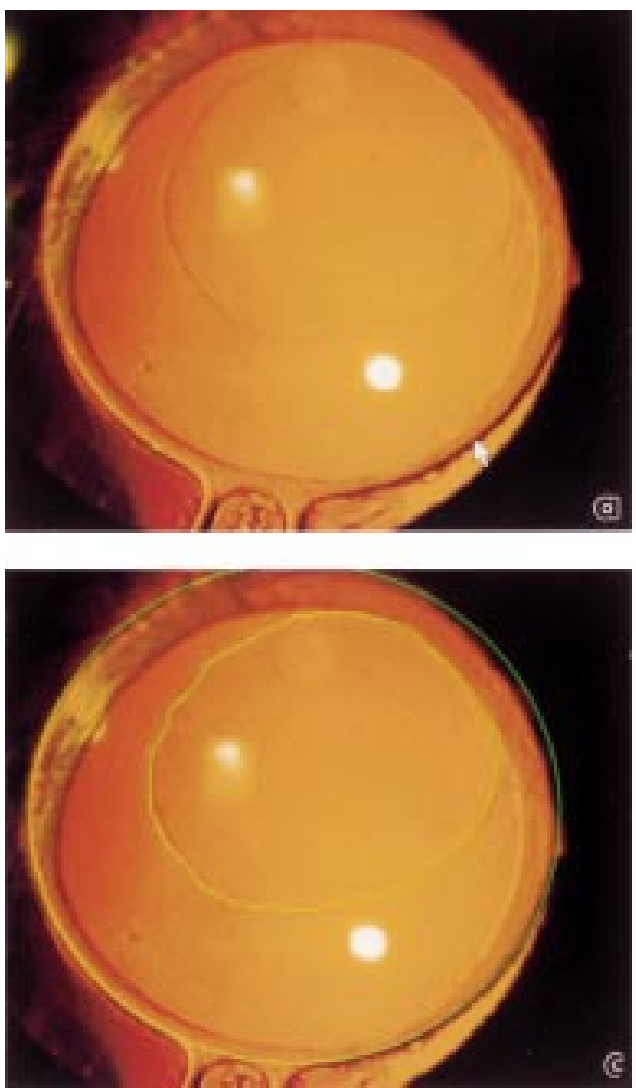

Figure 1 (a-d) EPCO application for the measurement of the PCCC area.

At 6 months, 1 year, and 2 years after surgery, pupils were dilated with a mixture of tropicamide and phenylephrine and the eyes were evaluated at the slit lamp. Standardised photographs of the pseudophakic anterior segment were obtained with a Nikon FS-2 digital slit lamp using retroillumination and lateral illumination. These pictures were processed for transfer to Photo-CD master disc (Eastman Kodak Company) by digital scanning allowing further analysis of the pictures for the measurement of the PCCC area. For this purpose, we used the computerised program EPCO (evaluation of posterior capsule opacification), a morphological scoring system for PCO. ${ }^{15}$ This program uses a standardised photodocumentation program whereby a morphological score, graded from 1 to 4 , is given to each area of opacification, thus making it possible to measure the density of PCO as a function of time. For the purpose of this study, the PCCC area was measured instead of the PCO area. To achieve this goal, we first defined the IOL surface by selecting three points along the IOL margin (Fig 1a, b). The calculated lens optic area was defined as $100 \%$. The PCCC area was delineated by a continuous line following the contours of the PCCC area (Fig 1c) and was considered as a grade 1 density area (Fig 1d). The program calculated the area as the product of the number of pixels in the marked area and the grade of density (which is 1 in our study) and related this to the IOL area; thus the PCCC area is calculated in relation to the size of the IOL. This was repeated at different times enabling us to evaluate the changes in PCCC surface as a function of time.
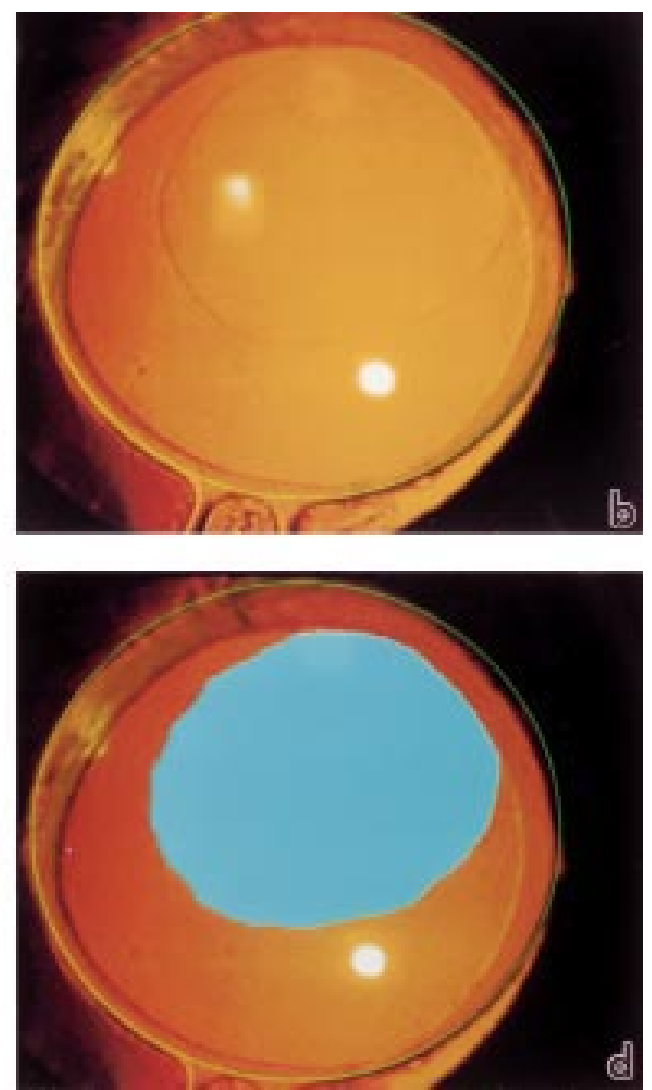

In the meantime, the photographs taken at different time intervals were evaluated by two observers for the presence of posterior capsule fibrosis or Elschnig pearl formation at the periphery of the capsular bag. Since the EPCO system was designed for the evaluation of PCO in the optical area, it was not used for this purpose.

EVALUATION OF CHANGES IN PCCC AREA IN TIME Pictures of good quality and suitable for interpretation were obtained from 13 eyes with a follow up of 6 months to 1 year (group I) and of 14 eyes with a follow up of 1-2 years (group II). Statistical analysis of the proportional changes in surface as a function of time was made by means of the paired $t$ test.

INFLUENCE OF PEARL FORMATION ON PCCC AREA AS A FUNCTION OF TIME

In order to evaluate if pearl formation within the capsular bag would influence the shape of the capsular bag and thus the surface of the PCCC area, two observers reviewed all photographic data for presence or absence of clinically evident LEC proliferation as a function of time. Statistical analysis was made by means of paired $t$ test and a Wilcoxon matched pairs signed ranks test.

\section{Results}

EVALUATION OF PCCC AREA AS A FUNCTION OF TIME

The changes in PCCC area in group I eyes with a postoperative follow up of 6 months to 1 year was not statistically significant $(p=0.11)$ 
Table 1 PCCC area at the different time periods in group I-IV

\begin{tabular}{lllll}
\hline Group & $n$ & Time 1 & Time 2 & Difference \\
\hline I & 13 & 0.360231 & 0.377046 & -0.016815 \\
II & 14 & 0.356714 & 0.35671 & 0.000143 \\
III & 19 & 0.360368 & 0.369684 & -0.00932 \\
IV & 8 & 0.35375 & 0.3587 & -0.00495 \\
\hline
\end{tabular}

Group I = evaluation of PCCC area in function of time: follow up of 6 months to 1 year. Group II = evaluation of PCCC area in function of time: follow up of 1 year to 2 years.

Group III = influence of pearl formation on PCCC area in function of time: evidences of increased pearl formation between two time intervals.

Group IV = influence of pearl formation on PCCC area in function of time: no evidences of increased pearl formation between two time intervals.

(Table 1). Neither was there a significant difference in PCCC area in the second group, with a postoperative follow up of 1-2 years $(\mathrm{p}=0.9)($ Table 1$)$.

INFLUENCE OF PEARL FORMATION ON PCCC AREA AS A FUNCTION OF TIME

Clinical evidence of LEC proliferation between two time intervals was observed in 19 eyes (group III). Figures 2a, b show an example of what was considered by the observers as clinical evidence of LEC proliferation. No clinical evidence of LEC proliferation between two time intervals was found in eight eyes (group IV). Figure 3a, b show an example of what the reviewers considered as clinical absence of LEC proliferation. No statistically significant difference in PCCC surface as a function of time was found in group III, where two time stages were compared in eyes presenting clini-
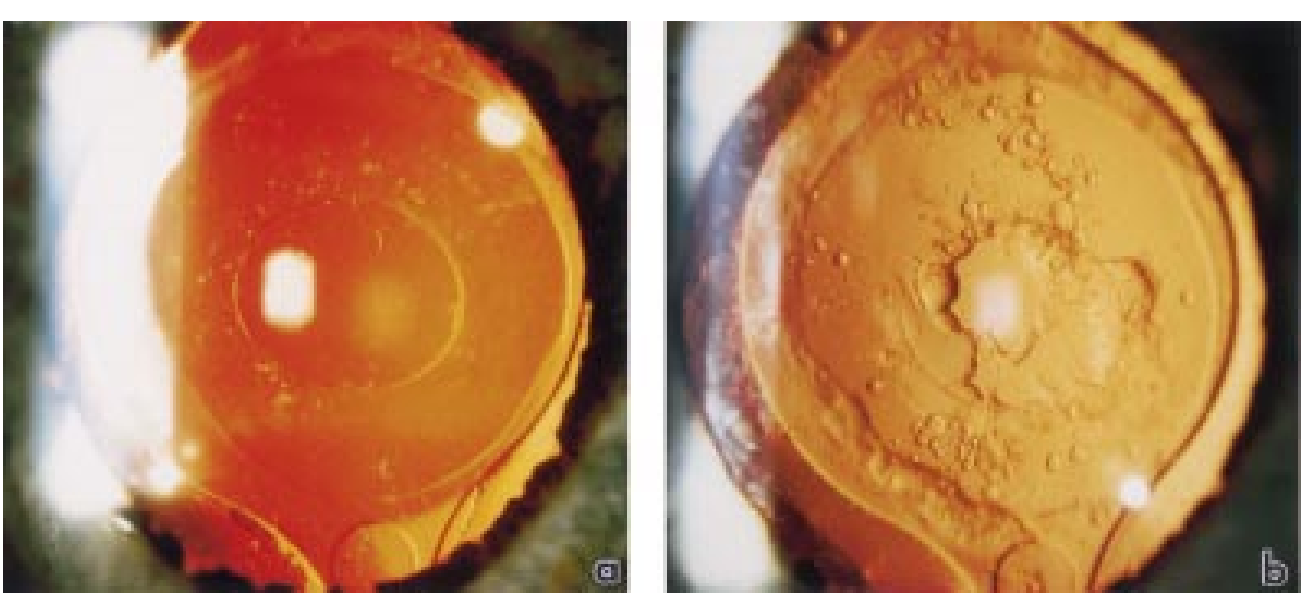

Figure $2(a, b)$ Example of what was considered as clinical evidence of LEC proliferation between two time intervals.

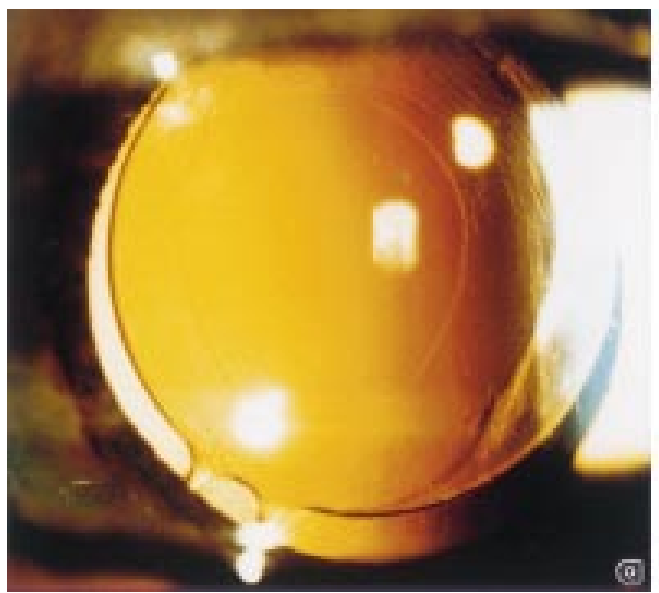

Figure 3 (a, b) Example of what was considered as clinical absence of LEC proliferation between two time intervals.

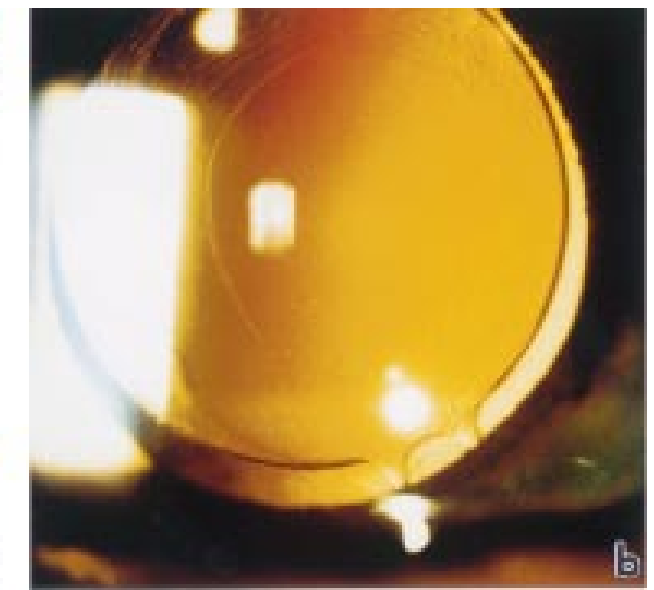

cal evidence of pearl formation $(p=0.27)$ (Table 1). Neither was there a statistically significant difference in group IV, where two time intervals were compared in eyes with no clinical evidence of pearl formation $(\mathrm{p}=0.53)$ (Table 1).

\section{Discussion}

PCCC has been introduced in cataract surgery for paediatric cataract extraction ${ }^{16}$ and for extracapsular surgery complicated by capsular disruption. ${ }^{17-19}$ It was meant to prevent the central opacification of the posterior capsule and thus to avoid secondary Nd:YAG laser posterior capsulotomy. This is a very commonly used technique for the treatment of after-cataract. Nevertheless, it is far from innocuous, since it causes increase in intraocular pressure, IOL damage, cystoid macular oedema, and retinal detachment. PCCC as a primary intervention has been proposed by Galand $e t a l^{10}$ to reduce the use of Nd:YAG laser capsulotomy. However, it was found by our group ${ }^{12}$ that $40 \%$ of the eyes with primary PCCC will present reclosure. As far as we know, no previous studies have been performed on the postoperative evolution of the PCCC area as a function of time and of LEC proliferation. We assumed that the size and shape of the PCCC area could change because of the presence of an IOL in the capsular bag and because of the presence of LEC 
proliferation. Whether the latter is the consequence of the former remains an open question. We first measured the changes in surface of the PCCC area without taking LEC proliferation into account. It must be stressed that for this study only eyes of patients without clinical or medical history, who underwent a successful cataract surgery, were considered. No statistically significant changes in PCCC surface could be found during the follow up period of 6 months to 1 year and of 1 year to 2 years. In some individual cases, however, there was a tendency of enlargement or reduction of PCCC area, but when we considered the overall group, these changes turned out not to be significant. Posterior convexity of the IOL, introduced to exert a certain degree of pressure on the posterior capsule of the bag and to prevent LECs growing, would theoretically induce a certain degree of enlargement of the PCCC. However, this was not found in our study, making the usefulness of this part of this lens design questionable.

Our second concern was to study the influence of LEC proliferation on the PCCC area as a function of time. Clinical evidence of increased LEC proliferation as a function of time was found in 19 out of the 27 eyes studied $(70 \%)$. Additionally, the longer the follow up, the higher the frequency of LEC proliferation. The explanation of this clinical observation remains speculative. A tentative explanation could be found by extrapolating the results of Rakic et al, ${ }^{20}$ who demonstrated that LECs are stimulated by removing the fibres during cataract surgery, suggesting that stress could be a stimulating factor for proliferation. For technical reasons, it is impossible to have a perfectly well matched IOL for each capsule of each patient. According to postmortem studies, human capsular bags vary in diameter from 9.5 to $11 \mathrm{~mm} .^{21}$ Therefore, the IOLs are manufactured large enough to secure stabile capsular fixation even for the largest capsular bags. Although not proved until now, one could assume that pressure exerted by the IOL haptics on the LECs, present in the capsular bag, could enhance LEC proliferation. It can thus be emphasised that the haptics of the modern "in the bag" IOLs stimulate LEC pro- liferation, while the optical part does not exert enough pressure to prevent LEC proliferation on the posterior capsular surface.

The authors wish to thank Rudy Leysen for his technical and photographic assistance.

1 Apple DJ, Solomon KD, Tetz MR, et al. Posterior capsule opacification. Surv Ophthalmol 1992;37:73-116.

2 Ohadi C, Moreira H, Mc Donnell PJ. Posterior capsule opacification. Curr Opin Ophthalmol 1991;2:46-52.

3 Kappelhof JP, Vrensen GFJM. The pathology of afterKappelhof JP, Vrensen GFJM. The pathology of after-
cataract; a minireview. Acta Ophthalmol 1992;Suppl cataract; ${ }_{2}$ a $13-24$.

4 Nishi O, Nishi K, Sakka Y, et al. Intercapsular cataract surgery with lens epithelial cell removal. Part IV: capsular fibrosis induced by poly(methylmethcrylate). $\mathcal{f}$ Cataract Refract Surg 1997;17:471-7.

5 Sterling S, Wood TO. Effect of intraocular lens convexity on posterior capsule opacification. I Cataract Refract Surg 1986;12:655-7.

6 Sellman TR, Lindstrom RL. Effect of a plano-convex posterior chamber lens on capsular opacification from Elschnig pearl formation. 7 Cataract Refract Surg 1988;14:68-73.

7 Born CP, Ryan DK. Effect of intraocular lens optic design on posterior capsular opacification. 7 Cataract Refract Surg 1990;16:188-91.

8 Legler UFC, Apple DJ, Assia EI, et al. Inhibition of posterior capsule opacification: the effect of colchicine in a sustained drug delivery system. I Cataract Refract Surg 1993;19:462-9.

9 Power WJ, Neylan D, Collum LMT. Daunomycin as an inhibitor of human lens epithelial cell proliferation in culture. F Cataract Refract Surg 1994;20:287-90.

10 Galand A, Van Cauwenberge F, Moosavi J. Posterior capsuorhexis in adult eyes with intact and clear capsules. f Cataract Refract Surg 1996;22:458-61.

11 Tassignon MJ, De Groot V, Smets RME, et al. Secondary closure of posterior continuous circular capsulotomy (capsulorhexis). F Cataract Refract Surg 1996;22:1200-5.

12 Tassignon MJ, De Groot V, Vervecken F, et al. Secondary closure of posterior continuous curvilinear capsulorhexis in normal eyes and eyes at risk for postoperative inflammation. 7 Cataract Refract Surg 1998;24:1333-8.

13 Van Cauwenberge F, Rakic JM, Galand A. Complicated posterior capsulorhexis: aetiology, management and outposterior capsulorhexis: aetiology, man
come. Br f Ophthalmol 1997;81:195-8.

14 De Groot V, Willekens B, Rakic JM, et al. Closure of posterior continuous curvilinear capsulorhexis (PCCC): an in vitro model study. Invest Ophthalmol Vis Sci 1998;39:S211.

15 Tetz MR, Auffarth GU, Sperker M, et al. Photographic image analysis system of posterior capsule opacification. $\mathcal{F}$ Cataract Refract Surg 1997;23:1515-20.

16 Gimbel HW. Posterior capsule tears using phacoemulsification: causes, prevention and management. Eur $\mathcal{F}$ Implant Refract Surg 1990;2:63-9.

17 Blumenthal M, Assia E, Neumann D. The round capsulorhexis capsulotomy and the rationale for $11.0 \mathrm{~mm}$ diameter IOL. Eur 7 Implant Refract Surg 1990;2:15-19.

18 BenEzra D, Paez JH. Congenital cataract and intraocular lenses. Am f Ophthalmol 1983;96:311-4.

19 Gimbel HV, DeBroff BM. Posterior capsulorhexis with optic capture: maintaining a clear visual axis after pediatric cataract surgery. 7 Cataract Refract Surg 1994;20:658-64.

20 Rakic JM, Galand A, Vrensen GFJM. Separation of fibres from the capsule enhances mitotic activity of human lens epithelium. Exp Eye Res 1997;64:67-72.

21 Galand A, Bonhomme L, Collee M. Direct measurement of the capsular bag. J Am Intra-ocular Implant Soc 1985;10: $475-6$ 